\title{
Frequency of TSC1 and TSC2 mutations in American, British, Polish and Taiwanese populations
}

\author{
JAROSŁAW JÓŹWIAK ${ }^{1}$, IWONA SONTOWSKA ${ }^{1}$ and RAFAŁ PŁOSKI ${ }^{2}$ \\ ${ }^{1}$ Department of Histology and Embryology, Center for Biostructure Research, Medical University of Warsaw, \\ PL-02004 Warsaw; ${ }^{2}$ Department of Medical Genetics, Medical University of Warsaw, PL-02091 Warsaw, Poland
}

Received January 30, 2013; Accepted June 10, 2013

DOI: $10.3892 / \mathrm{mmr} .2013 .1583$

\begin{abstract}
Tuberous sclerosis (TS) is caused by mutation of the tumor suppressor genes, tuberous sclerosis complex 1 (TSC1) or 2 (TSC2). The aim of the present study was to compare the frequency and types of TSC1 and TSC2 mutations in American, British, Polish and Taiwanese populations. A meta-analysis of 380 TS patients was performed. Significant differences were analyzed using the Chi-square test and one-way ANOVA analysis. Results showed a difference in frequency for the four populations analyzed. The frequency of TSCl mutations was twice as high in the American and British populations. However, there were no significant differences in the types of mutations, with insertions of $>1$ nucleotide being the least frequent. Additionally, in an analysis of the complexity of nucleotide sequences it was demonstrated that the level of sequence complexity in the Polish population was significant higher compared to the remaining populations. Concerning strand bias, in the case of two types of substitutions, $\mathrm{C}>\mathrm{G} / \mathrm{G}>\mathrm{C}$ and $\mathrm{C}>\mathrm{T} / \mathrm{G}>\mathrm{A}$, the ratio of corresponding mutations on the two DNA strands was approximately $3: 1$ and $2: 1$. In the present study, an increased frequency of $\mathrm{C}>\mathrm{G} / \mathrm{G}>\mathrm{C}$ and $\mathrm{C}>\mathrm{T} / \mathrm{G}>\mathrm{A}$ mutations in the coding strand was found in the analyzed populations. However, additional studies and larger patient cohorts are required to verify these results.
\end{abstract}

\section{Introduction}

Tuberous sclerosis (TS), an autosomal dominant disease, is caused by mutation of one of the two tumor suppressor genes, tuberous sclerosis complex 1 (TSC1) or 2 (TSC2), encoding hamartin (TSC1) and tuberin (TSC2), respectively. TSC1,

Correspondence to: Dr Jarosław Jóźwiak, Department of Histology and Embryology, Center for Biostructure Research, Medical University of Warsaw, ul. Chalubinskiego 5, PL-02004 Warsaw, Poland

E-mail: jaroslaw.jozwiak@gmail.com

Key words: tuberous sclerosis, tuberous sclerosis complex 1, tuberous sclerosis complex 2, mutation frequency located on chromosome 9q34, contains 23 exons and an 8.6 kb mRNA transcript, while TSC2 is located on chromosome 16p13.3 and contains 41 exons. Two thirds of the TS cases are sporadic. Based on the relatively high incidence rate of 1:6,000, the disease is considered common in the general population. However, no studies comparing the frequency of mutation sites in different populations or evaluating the segregation of mutations are currently available.

As mentioned above, the disease develops when one of the two tumor suppressor genes, $T S C 1$ or TSC2, is mutated. This is the result of close cooperation of encoded proteins within the cell. Hamartin and tuberin form an intracellular complex responsible for the inhibition of Ras homologue enriched in brain (Rheb). Subsequently, Rheb activates the mammalian target of rapamycin (mTor) kinase, which is responsible for the regulation of protein translation. Thus, when the TS complex has not been formed or is non-functional, Rheb inhibition is inefficient and mTor promotes cell cycle progression, leading to uncontrolled proliferation and, possibly, tumor development.

The aim of the present study was to compare the frequency of TSC1 and TSC2 mutations, as well as the types of specific mutations presenting in different populations. Therefore, a meta-analysis of five large-scale sequencing studies (1-5) was performed, including TS patients from four distinct populations: American, British, Polish and Taiwanese.

\section{Materials and methods}

Taiwanese population. Eighty-four unrelated patients with a familial or sporadic form of TS were included in the study by Hung et al (5). Denaturing high-performance liquid chromatography (DHPLC) and direct sequencing were used for mutation detection. Mutations were identified in a total of 64 patients. The diagnostic criteria used were according to Roach et al (6).

American and Polish population. Two hundred and twenty-four unrelated patients with a familial or sporadic form of TS were included in the study by Dabora et al (4). DHPLC, long-range polymerase chain reaction (PCR) and quantitative PCR were used for mutation detection. Mutations were identified in a total of 186 patients. The diagnostic criteria used were according to Roach et al (6). 
American population. One hundred and twenty-six unrelated patients with a familial or sporadic form of TS were included in the study by Niida et al (3). Single-stranded conformational polymorphism (SSCP) method followed by direct sequencing was applied for mutation detection. The diagnostic criteria used were according to Gomez (7) and Roach et al (8).

British population. One hundred and fifty unrelated patients with a familial or sporadic form of TS were included in the study by Jones et al $(1,2)$. SSCP, heteroduplex analysis, pulsed-field gel electrophoresis, Southern blot analysis and long PCR were applied for mutation detection. The diagnostic criteria used were according to Roach et al (6).

Cohort of patients. Large rearrangements and polymorphisms were excluded from this meta-analysis. Eventually, a group of 381 patients was obtained, in whom small mutations in TSC1 or TSC2 were detected. The cohort of patients included 136 American, 98 British, 83 Polish and 64 Taiwanese patients. Due to insufficient data, one of the patients from the American population (with a TSC2 mutation) was not included in this meta-analysis.

\section{Results}

Frequency of TSC1 and TSC2 mutations in the different populations. One of the most obvious results of this meta-analysis was the fact that the frequency of TSC1 and TSC2 mutations was different in the analyzed populations. There were significant differences in the prevalence of TSC1 and TSC2 mutations between Polish/Taiwanese populations and American/British populations (Table I). Approximately 9.6 and $12.7 \%$ of Polish and Taiwanese patients, respectively, had TSC 1 mutations, while their American and British counterparts exhibited an approximately 2-fold higher ratio of mutated hamartin (26.5 and $22.4 \%$, respectively). Statistical analysis using the Chi-square test showed that there were significant differences between these populations $(\mathrm{P}=0.011660)$.

Types of mutations. There were no significant differences in the types of mutations occurring in the affected genes in the populations analyzed (Chi-square test, $\mathrm{P}=0.692681$ ). The majority of the mutations were single nucleotide changes. The second most important type of mutations were deletions of $>1$ nucleotide. The third type were insertions of single nucleotides (in the American and Taiwanese populations) or deletions of single nucleotides (in the Polish and British populations). There were also single deletions (in the American and Taiwanese populations) or single insertions (in the British population) and both single or multiple insertions. In all the patients analyzed, insertions of $>1$ nucleotide were the least frequent. The results are shown in Table II.

However results of this study may not completely reflect the actual distribution of mutations, since the original studies used in this meta-analysis employed different methods for the detection of mutations. Additionally, comparative studies have shown that DHPLC is a more sensitive method compared to $\operatorname{SSCP}(9,10)$.
Table I. Frequency of TSC1 and TSC2 mutations in the analyzed populations.

\begin{tabular}{lccr}
\hline & \multicolumn{2}{c}{ Frequency of mutations, $\mathrm{n}(\%$ of total $)$} \\
\cline { 2 - 4 } Population & TSC1 & TSC2 & Total \\
\hline American & $36(26.5)$ & $100(73.5)$ & 136 \\
British & $22(22.4)$ & $76(77.6)$ & 98 \\
Polish & $8(9.6)$ & $75(90.4)$ & 83 \\
Taiwanese & $9(12.7)$ & $55(87.3)$ & 64 \\
Total & $74(19.5)$ & $306(80.5)$ & 380 \\
\hline
\end{tabular}

Analysis of sequences flanking the mutations. The application analyzing the complexity of nucleotide sequences, Linguistic Complexity (available at: http://csweb.haifa.ac.il/ library/\#complex.html), was used to analyze the degree of complexity of the sequences flanking the mutations. Fifteen nucleotides located directly upstream and downstream of the mutation were analyzed. The level of sequence complexity in sequences flanking the mutation in the Polish population was found to be statistically higher compared to the remaining populations (Fig. 1). One-way Anova analysis was used to show that the differences were statistically significant $(\mathrm{P}=0.01695)$.

Frequency of mutation types in the different populations. No statistically significant differences were observed in the frequency of mutation types in individual populations (Fig. 2). The most frequent type of mutations were deletions spanning $>1$ nucleotide.

Frequency of pair substitutions. The frequency of pair substitutions was analyzed in the four populations. The ratio of corresponding mutations (e.g., $\mathrm{C}>\mathrm{G}$ and $\mathrm{G}>\mathrm{C}$ ) is usually approximately 1:1 because if susceptibility of the two DNA strands to a given type of mutation is the same, there should be an equal number of $\mathrm{C}>\mathrm{G}$ mutations on both strands. However, a $\mathrm{C}>\mathrm{G}$ mutation on the coding strand is detected as $\mathrm{G}>\mathrm{C}$ on a transcribed strand. Notably, in the case of two types of substitutions $(\mathrm{C}>\mathrm{G} / \mathrm{G}>\mathrm{C}$ and $\mathrm{C}>\mathrm{T} / \mathrm{G}>\mathrm{A})$, the ratio of the corresponding mutations was approximately $3: 1$ and $2: 1$, respectively. The difference was statistically significant $\left(\mathrm{P}<10^{-6}\right.$ for $\mathrm{C}>\mathrm{T} / \mathrm{G}>\mathrm{A}$ and $\mathrm{P}=0.037$ for $\mathrm{C}>\mathrm{G} / \mathrm{G}>\mathrm{C}$ using the Chi-square test; Fig. 3).

\section{Discussion}

The potential differences in the distribution of mutations between distinct populations including Polish and Taiwanese were investigated in the present study.

Notably, statistically significant differences were found between the frequency of TSC1 and TSC 2 mutations between Polish/Taiwanese populations and American/British populations. The TSCl mutation is associated with a milder clinical presentation of the disease. Thus, it is suggested that the higher incidence of TSC 2 mutations in Polish and Taiwanese patients 
Table II. Types of mutations found in the cohort of patients analyzed. ${ }^{\mathrm{a}}$

\begin{tabular}{lcccccr}
\hline & \multicolumn{5}{c}{ Types of mutations, n (\% of total) } \\
\cline { 2 - 6 } Population & Deletions $>1$ & SNP & Insertions $>1$ & Single insertions & Single deletions & Total \\
\hline American & $36(26.47)$ & $78(57.35)$ & $2(1.47)$ & $13(9.56)$ & $7(5.15)$ & 136 \\
British & $21(21.43)$ & $58(58.19)$ & $4(4.08)$ & $6(6.12)$ & $9(9.18)$ & 98 \\
Polish & $16(19.28)$ & $55(66.27)$ & $3(3.61)$ & $3(3.61)$ & $6(7.23)$ & 83 \\
Taiwanese & $12(18.75)$ & $38(59.38)$ & $2(3.13)$ & $7(10.94)$ & $5(7.81)$ & 64 \\
Total & 85 & 229 & 11 & 29 & 27 & 381 \\
\hline
\end{tabular}

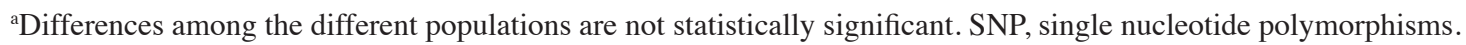

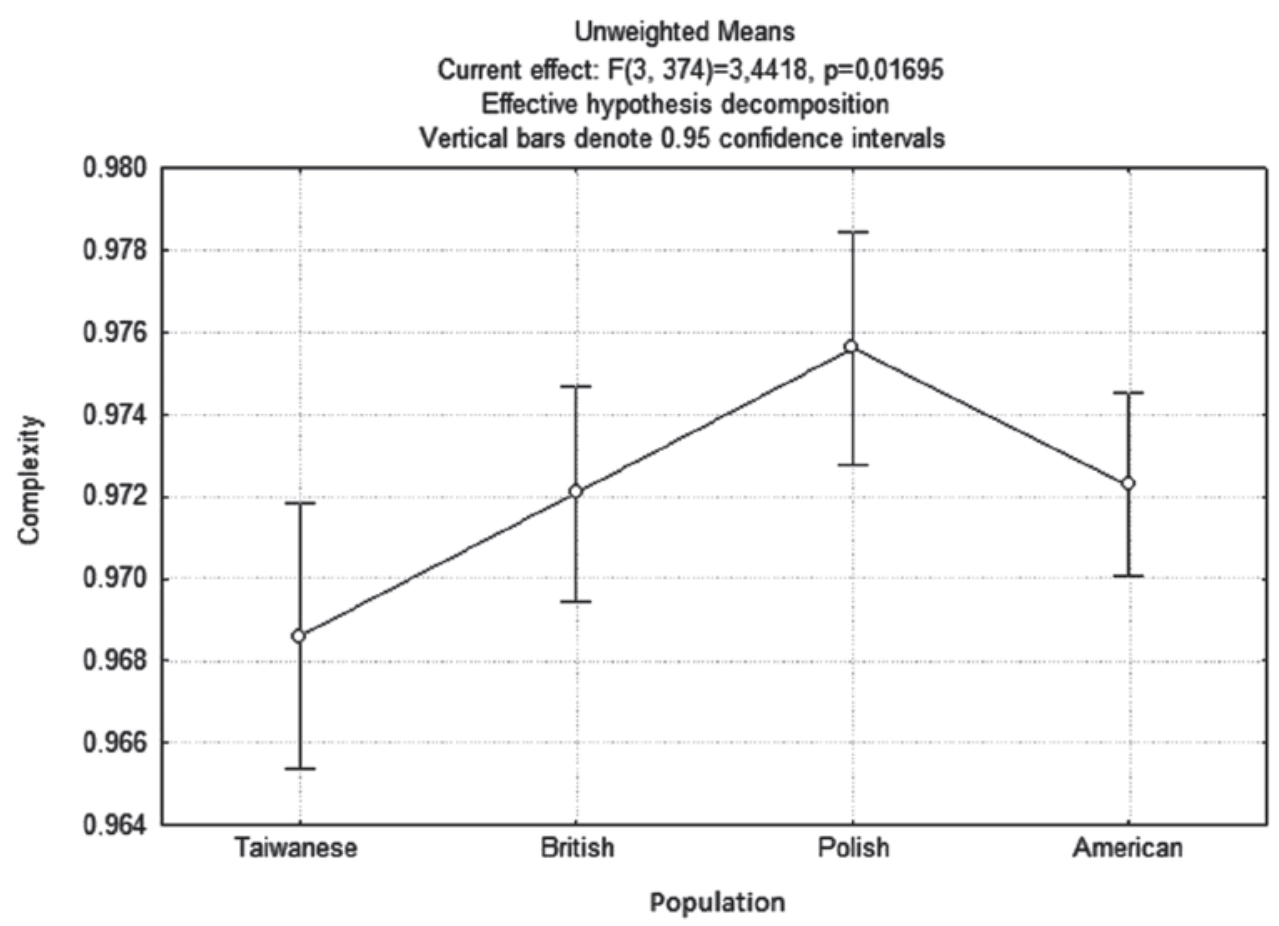

Figure 1. Mean complexity of nucleotide sequences flanking the mutations.

may be explained by a more pronounced clinical picture. Additionally, the higher ratio of TSC1 mutations in British and American patients might be due to the highly efficient patient organizations in these countries, working actively to increase disease awareness among the population. According to Dabora et al (4), patients with sporadic TSC1 mutations usually have milder disease compared to patients with TSC 2 mutations. Particularly, they present with less frequent seizures and moderate to severe mental retardation, fewer subependymal nodules and cortical tubers, less severe kidney involvement, no retinal hamartomas, and less severe facial angiofibroma.

In the present study, the level of sequence complexity in sequences flanking the mutation in the Polish population was found to be significantly higher compared to the remaining populations analyzed. This was an interesting finding, since mutations tend to generally appear in the sequences of lower complexity. This finding suggests that there is a factor that contributes to the occurrence of mutations in the Polish population, where sequences are more complex. The identification of this mutagenic factor, the activity of which is particularly notable in more complex sequences, and the prevention of its activity could lead to the reduction of TS morbidity in Poland, and would also provide a better understanding of this disease.

Pleasance et al (11) reported the effect of substances present in cigarette smoke on gene modifications in small cell lung cancer cases. According to results of this study, $\mathrm{G}>\mathrm{T}$ transversions caused by polycyclic aromatic hydrocarbons occur more often in the loci of methylated $\mathrm{CpG}$ dinucleotides in TP53, and guanine, which is subjected to transversion into cytosine, is more often preceded by adenine (11). Additional studies describe the formation of $\mathrm{C}>\mathrm{T}$ and $\mathrm{CC}>\mathrm{TT}$ mutations in skin cancer cases under the influence of ultraviolet (UV) radiation. Radiation 


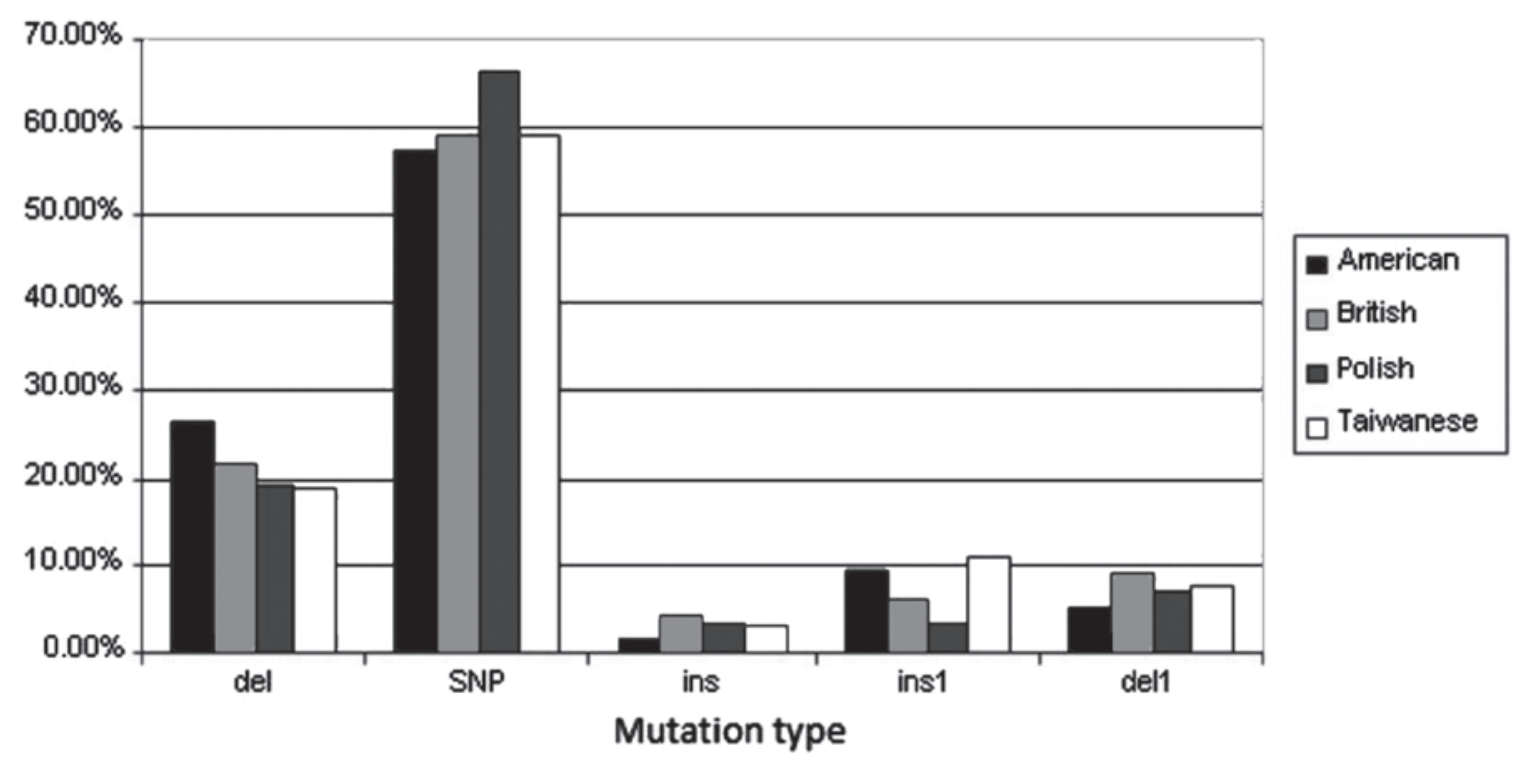

Figure 2. Distribution of mutation types in the four populations analyzed.

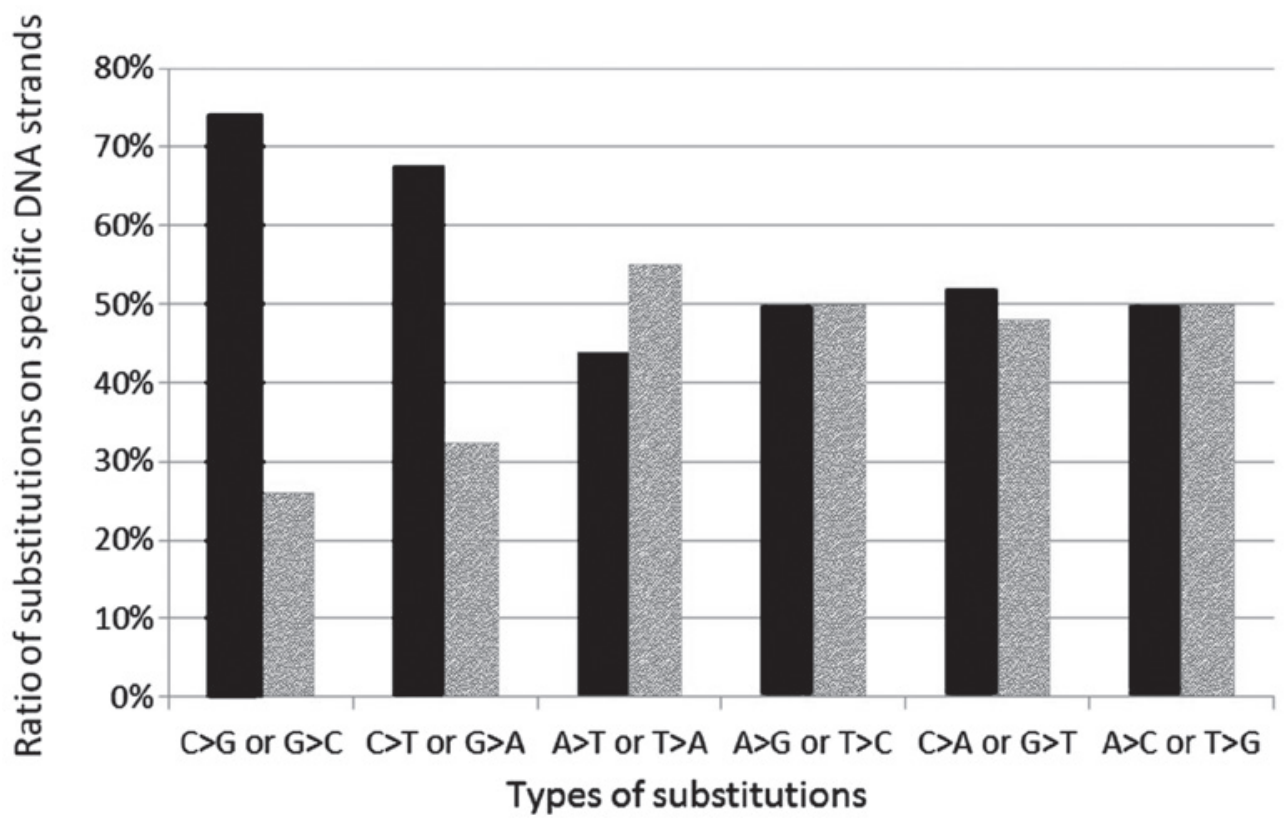

Figure 3. Ratio of individual mutation types in the mutation pairs in all the patients analyzed.

leads to the formation of covalent bonds between adjacent pyrimidines, and subsequent mutations usually appear in dipirimidine sequences $(12,13)$. It has also been noted that the same mutations, susceptible to UV radiation, are more frequent in $\mathrm{CpG}$ dinucleotides $(13,14)$.

Notably, the ratio of corresponding mutations was not found to be equal (1:1), but significantly different in the case of $\mathrm{C}>\mathrm{G} / \mathrm{G}>\mathrm{C}$ and $\mathrm{C}>\mathrm{T} / \mathrm{G}>\mathrm{A}$ pairs. Substitutional strand asymmetry results from transcription and replication, with both of these processes involving annealing of the two DNA strands. Substitutional asymmetry resulting from replication has been described in bacteria and human mitochondrial
DNA $(15,16)$, while substitutional asymmetry resulting from transcription has been described in mammals (17). In the present study, an increased frequency of $\mathrm{C}>\mathrm{G} / \mathrm{G}>\mathrm{C}$ and $\mathrm{C}>\mathrm{T} / \mathrm{G}>\mathrm{A}$ mutations in the coding strand was found in the analyzed populations. Compared to 4,590 genes evaluated by Mugal et al (18), where the relative difference between mutation frequencies on both strands $(\mathrm{C}>\mathrm{T} / \mathrm{G}>\mathrm{A})$ was rarely shown to be $>35 \%, T S C 1$ and TSC 2 appear to be particularly prone to strand bias, as the relative difference reaches $35 \%$ (18). However, additional studies and the analysis of larger population groups are needed for further investigation of this phenomenon. 


\section{References}

1. Jones AC, Daniells CE, Snell RG, Tachataki M, Idziaszczyk SA, Krawczak M, Sampson JR and Cheadle JP: Molecular genetic and phenotypic analysis reveals differences between TSC1 and TSC2 associated familial and sporadic tuberous sclerosis. Hum Mol Genet 6: 2155-2161, 1997.

2. Jones AC, Shyamsundar MM, Thomas MW, Maynard J, Idziaszczyk S, Tomkins S, Sampson JR and Cheadle JP: Comprehensive mutation analysis of TSC1 and TSC2 - and phenotypic correlations in 150 families with tuberous sclerosis. Am J Hum Genet 64: 1305-1315, 1999.

3. Niida Y, Lawrence-Smith N, Banwell A, Hammer E, Lewis J, Beauchamp RL, Sims K, Ramesh V and Ozelius L: Analysis of both TSC1 and TSC2 for germline mutations in 126 unrelated patients with tuberous sclerosis. Hum Mutat 14: 412-422, 1999.

4. Dabora SL, Jozwiak S, Franz DN, Roberts PS, Nieto A, Chung J, Choy YS, Reeve MP, Thiele E, Egelhoff JC, Kasprzyk-Obara J, Domanska-Pakiela D and Kwiatkowski DJ: Mutational analysis in a cohort of 224 tuberous sclerosis patients indicates increased severity of TSC 2 , compared with TSC1, disease in multiple organs. Am J Hum Genet 68: 64-80, 2001.

5. Hung CC, Su YN, Chien SC, Liou HH, Chen CC, Chen PC Hsieh CJ, Chen CP, Lee WT, Lin WL and Lee CN: Molecular and clinical analyses of 84 patients with tuberous sclerosis complex. BMC Med Genet 7: 72, 2006.

6. Roach ES, Gomez MR and Northrup H: Tuberous sclerosis complex consensus conference: revised clinical diagnostic criteria. J Child Neurol 13: 624-628, 1998.

7. Gomez MR: Phenotypes of the tuberous sclerosis complex with a revision of diagnostic criteria. Ann N Y Acad Sci 615: 1-7, 1991.

8. Roach ES, Smith M, Huttenlocher P, Bhat M, Alcorn D and Hawley L: Diagnostic criteria: tuberous sclerosis complex. Report of the Diagnostic Criteria Committee of the National Tuberous Sclerosis Association. J Child Neurol 7: 221-224, 1992.

9. Eng C, Brody LC, Wagner TM, Devilee P, Vijg J, Szabo C Tavtigian SV, Nathanson KL, Ostrander E and Frank TS; Steering Committee of the Breast Cancer Information Core (BIC) Consortium: Interpreting epidemiological research: blinded comparison of methods used to estimate the prevalence of inherited mutations in BRCA1. J Med Genet 38: 824-833, 2001.
10. Bunn CF, Lintott CJ, Scott RS and George PM: Comparison of SSCP and DHPLC for the detection of LDLR mutations in a New Zealand cohort. Hum Mutat 19: 311, 2002.

11. Pleasance ED, Stephens PJ, O'Meara S, McBride DJ, Meynert A, Jones D, Lin ML, Beare D, Lau KW, Greenman C, Varela I, Nik-Zainal S, Davies HR, Ordoñez GR, Mudie LJ, Latimer C, Edkins S, Stebbings L, Chen L, Jia M, Leroy C, Marshall J, Menzies A, Butler A, Teague JW, Mangion J, Sun YA, McLaughlin SF, Peckham HE, Tsung EF, Costa GL, Lee CC, Minna JD, Gazdar A, Birney E, Rhodes MD, McKernan KJ, Stratton MR, Futreal PA and Campbell PJ: A small-cell lung cancer genome with complex signatures of tobacco exposure. Nature 463: 184-190, 2010.

12. Daya-Grosjean L and Sarasin A: The role of UV induced lesions in skin carcinogenesis: an overview of oncogene and tumor suppressor gene modifications in xeroderma pigmentosum skin tumors. Mutat Res 571: 43-56, 2005.

13. Pleasance ED, Cheetham RK, Stephens PJ, McBride DJ, Humphray SJ, Greenman CD, Varela I, Lin ML, Ordóñez GR, Bignell GR, Ye K, Alipaz J, Bauer MJ, Beare D, Butler A, Carter RJ, Chen L, Cox AJ, Edkins S, Kokko-Gonzales PI, Gormley NA, Grocock RJ, Haudenschild CD, Hims MM, James T, Jia M, Kingsbury Z, Leroy C, Marshall J, Menzies A, Mudie LJ, Ning Z, Royce T, Schulz-Trieglaff OB, Spiridou A, Stebbings LA, Szajkowski L, Teague J, Williamson D, Chin L, Ross MT, Campbell PJ, Bentley DR, Futreal PA and Stratton MR: A comprehensive catalogue of somatic mutations from a human cancer genome. Nature 463: 191-196, 2010.

14. Pfeifer GP, You YH and Besaratinia A: Mutations induced by ultraviolet light. Mutat Res 571: 19-31, 2005.

15. Lobry JR: Asymmetric substitution patterns in the two DNA strands of bacteria. Mol Biol Evol 13: 660-665, 1996.

16. Tanaka M and Ozawa T: Strand asymmetry in human mitochondrial DNA mutations. Genomics 22: 327-335, 1994.

17. Green P, Ewing B, Miller W, Thomas PJ; NISC Comparative Sequencing Program, Green ED: Transcription-associated mutational asymmetry in mammalian evolution. Nat Genet 33: 514-517, 2003.

18. Mugal CF, von Grünberg HH and Peifer M: Transcription-induced mutational strand bias and its effect on substitution rates in human genes. Mol Biol Evol 26: 131-142, 2009. 